\title{
DESENVOLVIMENTO DE UM VIDEOGAME EDUCACIONAL NA ÁREA DE FISIOLOGIA HUMANA
}

\author{
Gutemberg de Almeida Borges ${ }^{1}$; Roberto Almeida Bittencourt ${ }^{2}$; \\ 1. Bolsista PIBIC/CNPq, Graduando em Engenharia de Computação, Universidade Estadual de Feira de Santana, e- \\ mail: gutem.borges@gmail.com \\ 2. Orientador, Departamento de Ciências Exatas, Universidade Estadual de Feira de Santana, e-mail: roberto@uefs.br
}

PALAVRAS-CHAVE: jogos educativos; fisiologia humana; videogames.

\section{INTRODUÇÃO}

Construir um ambiente de aprendizagem adequado e qualificado é um grande desafio para as instituições de ensino. Estudantes enfrentam questões de motivação provocadas por fatores como: i) deficiências prévias de formação; ii) infraestrutura escolar inadequada; iii) professores com qualificação deficiente; iv) diferentes interesses pessoais; v) um modelo de ensino-aprendizagem excessivamente concentrado no professor; vi) foco na memorização de conteúdos; vii) segmentação do conhecimento em disciplinas estanques; viii) didática baseada somente em aulas expositivas.

Quando ponderamos sobre o ensino e aprendizagem de ciências biológicas nos níveis fundamental e médio a situação não se difere. Por envolver conceitos complexos e abstratos, e em alguns casos, de difícil compreensão. Fisiologia, por sua vez, tem seus conceitos distribuídos em várias disciplinas da Educação Básica, dentre elas Biologia, Química, Ciências e Educação Física. Seu objetivo é explicar os fatores físicos e químicos que são responsáveis pela origem, desenvolvimento e progressão da vida, despertando o interesse dos estudantes da educação básica (Guyton \& Hall, 2006).

De acordo com os Parâmetros Curriculares Nacionais para o Ensino Médio (PCNEM) do Ministério da Educação (2000), ao concluir o ensino médio, o estudante deve ter o domínio dos códigos, conceitos e métodos desta ciência, de modo a ampliar sua compreensão das problemáticas que o rodeiam, especialmente em relação à vida humana. Rosa et. al. (2013) destacam a importância da inserção da Fisiologia, ainda pobremente trabalhada na educação básica. É evidente a importância de se trabalhar os conteúdos de Fisiologia Humana em sala de aula, uma vez que os mesmos ajudam na formação crítica do cidadão, além de proporcionar o conhecimento do corpo humano, fator fundamental para a manutenção da saúde e do bem estar (Campos et. al., 2003).

A motivação é um dos elementos centrais a se trabalhar neste contexto, nos levando a: i) refletir sobres materiais e ferramentas que poderiam ser utilizados para aumenta-la nos estudantes do ensino médio; ii) questionar as melhores abordagens de ensino-aprendizagem utilizadas pelos professores para aumentar a retenção de conhecimento; iii) questionar sobre organizações curriculares mais integradas, mais interdisciplinares, que proporcionem experiências significativas mais próximas do cidadãos ou profissionais.

Por outro lado, motivação para jogar videogames não costuma faltar entre a geração atual de estudantes, especialmente entre adolescentes. Jogos são parte do universo dos estudantes: muitos jovens, seduzidos pelos jogos digitais, permanecem longos períodos totalmente empenhados nos desafios e fantasias destes artefatos de mídia, dando a impressão de que são imunes a distrações, e que nada é capaz de 
desconcentrá-los (Savi \& Ulbricht, 2008). Conseguir desviar a atenção que os estudantes dão aos jogos para atividades educacionais não é tarefa simples. Com isso, tem aumentado o número de trabalhos de pesquisa que tentam encontrar formas de unir ensino e diversão através do desenvolvimento de jogos educacionais.

Por proporcionarem práticas educacionais atrativas e inovadoras, onde o aluno tem a chance de aprender de forma mais ativa, dinâmica e motivadora, os jogos educacionais podem se tornar auxiliares importantes do processo de ensino e aprendizagem (Savi \& Ulbricht, 2008). E o presente trabalho atua neste âmbito ao apresentar uma ferramenta de ensino e aprendizagem com o objetivo de estimular a motivação dos alunos a construir sua aprendizagem de forma colaborativa e ativa. Trata-se do jogo Body, uma versão digital de um jogo físico de tabuleiro para auxiliar o ensino de Biologia nas escolas do ensino médio, abordando conceitos da área de Fisiologia Humana.

\section{METODOLOGIA}

A construção do jogo foi ancorada no processo de aprendizagem de estudantes do ensino médio, na consultoria e participação de especialistas da Universidade Estadual de Feira de Santana (UEFS), tanto da área de biologia, desenvolvedores do jogo físico, como da área de computação, para o seu desenvolvimento virtual. $\mathrm{O}$ processo constou das seguintes etapas: concepção do jogo físico, design do jogo digital, construção do jogo usando a plataforma Unity e validação preliminar com os especialistas.

A primeira etapa foi a de concepção do jogo físico no qual o jogo digital se baseia. Esta etapa ocorreu através de reuniões com os pesquisadores da área de Biologia que desenvolveram o jogo físico, da experimentação com protótipos físicos e da validação com professores e estudantes do ensino médio. Nesta etapa, os requisitos do jogo digital foram documentados com base nas regras e mecânicas do jogo físico e foram listadas em um quadro de user stories (funcionalidades) e em uma To-Do List.

A segunda etapa foi o design do jogo. Para tanto, utilizou-se um Game Design Canvas (GDC), método que torna mais simples e rápido o processo de design e prototipação (Carey, 2015). Este GDC continha as seguintes colunas: definições, conceito, jogabilidade, controle, protagonista, NPCs, mecânica e mundo.

Na terceira etapa, a de desenvolvimento e construção do jogo, utilizou-se uma metodologia ágil. Esta etapa foi composta pelo design das interfaces e do modelo de jogo, feitos em paralelo à codificação. Isto foi facilitado pelo ambiente de desenvolvimento Unity, que, além de permitir programação das mecânicas, regras e funcionalidades do jogo, também possibilita a inserção e a modelagem de sprites. $\mathrm{O}$ protótipo do jogo foi então construído e testado, programando os scripts em linguagem C\# e utilizando os assets. Ainda foram utilizados alguns softwares de edição de imagens para auxiliar na confecção de sprites e backgrounds.

Por fim, na quarta e última etapa, o protótipo foi levado de volta à equipe que desenvolveu o jogo físico, para validação. Pequenas mudanças foram sugeridas para melhorar a interface e a jogabilidade. De modo geral, o protótipo foi bem aceito pelos especialistas da área de Biologia. 


\section{RESULTADOS}

Como resultados do trabalho tem-se a concepção do design do jogo, obtido inicialmente da análise do jogo físico tendo seus requisitos adaptados e conceituados para uma versão digital, e o protótipo digital feito tomando como base este design detalhado e apropriado para confecção do game, visando sua primeira versão.

Por se tratar de uma implementação digital de um jogo físico pré-existente, o jogo tem seu design fortemente baseado nele, aliado a decisões específicas de engines de jogos, plataformas-alvo e interface. Dentre os dados adquiridos no fim do processo de concepção de design podemos destacar a listagem das principais funcionalidades do jogo, a nível de implementação, no quadro de user stories e a descrição detalhada e completa do jogo no GDC, compreendida nos tópicos: i) Conceito de Jogo; ii) Regras do Jogo; iii) Público Alvo; iv) Ambiente de Jogo; v) Personagens; vi) Jogabilidade; vii) Interface, Controle e Mecânica; viii) Aspectos Educacionais.

O jogo Body pode ser compreendido pelas seguintes regras: i) Jogo de 4 a 6 jogadores; ii) Cada jogador começa com a mesma quantidade de órgãos e sorteia uma carta de objetivo; iii) Os objetivos vão desde a conquistas de sistemas a eliminação de jogadores oponentes; iv) O jogador somente ataca de um órgão seu que faça fronteira, através de vizinhanças ou trilhas, com um órgão do adversário; v) O adversário, para se defender, responderá uma questão presente na carta de ataque sobre fisiologia, do órgão atacado; vi) Vence o jogador que primeiramente conquistar seu objetivo.

Para o protótipo foi desenvolvida uma versão para plataforma desktop, onde é jogado por todos os participantes em um único computador. O protótipo deste jogo implementa as funcionalidades consideradas mais importantes para sua primeira versão: i) Partidas com quatro jogadores; ii) Detecção de colisão com os órgãos vizinhos; iii) Distribuição das cartas de órgãos e objetivos; iv) As trilhas são de acordo com o sistema circulatório e endócrino; v) O jogador vermelho sempre começa; vi) A única ação de cada jogador em seu turno é atacar um adversário em um órgão vizinho; viii) Uso de cartas de ataque/pergunta; ix) Fim de jogo ao conquistar um objetivo.

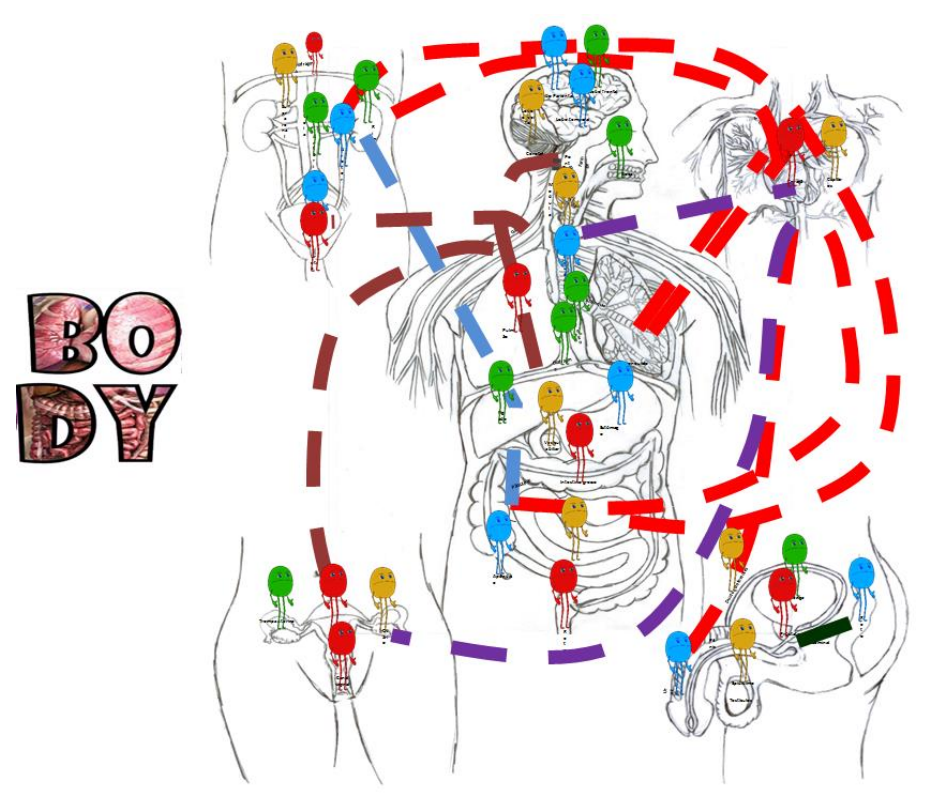

Figura 1: Tabuleiro de Jogo. 
O jogo segue um conjunto de regras e, na tela de sua aplicação, são mostrados elementos como tabuleiro e peças (ver Figura 1). De forma intuitiva e seguindo as regras, o jogador poderá realizar jogadas através de movimentações e ataques a órgãos vizinhos de adversários. O primeiro a alcançar seu objetivo, tirado nas cartas, será o vencedor. Importante ressaltar que o jogo já foi prototipado em sua versão física e testado com estudantes de algumas escolas. Com base nas experiências dos estudantes e do feedback recebido, o jogo foi validado e melhorado. Assim, o jogo atual já tem estas melhorias implementadas.

\section{CONSIDERAÇÕES FINAIS}

Este trabalho apresentou uma ferramenta para ensinar e aprender fisiologia humana no nível do ensino médio: o jogo digital Body, desenvolvido no Unity para a plataforma desktop. No Body, o jogador se envolve em uma atividade divertida e desafiadora ao mesmo tempo em que aprende os conteúdos da fisiologia, da anatomia, dos órgãos e dos sistemas do corpo humano.

O processo de desenvolvimento foi beneficiado pelo uso do GDC, tanto para definir de forma organizada as principais características do jogo como a flexibilidade para alterá-las. Outra lição aprendida foi o uso do processo ágil, que fez iniciar mais rapidamente o desenvolvimento do jogo, apesar das possíveis mudanças de projeto no decorrer da implementação. Por outro lado, talvez a mais importante das lições tenha sido sobre o papel educacional que um jogo pode adquirir.

Em trabalhos futuros, pretende-se implementar novas funcionalidades no jogo Body, assim como melhorar as já existentes. Melhorias como criar mais cartas de perguntas e objetivos, inserir mais jogadores e ações, mais territórios e órgãos, como também permitir o jogo em rede, para cada participante jogar em diferentes dispositivos. Outro trabalho futuro relevante, que pretende-se realizar, é uma avaliação mais detalhada da utilização do jogo por professores e estudantes do ensino médio.

\section{REFERÊNCIAS}

GUYTON, A.C.; HALL, J.E. 2006. Tratado de Fisiologia Médica. Rio de Janeiro, Elsevier.

MEC, MINISTÉRIO DA EDUCAÇÃO. 2000. Parâmetros curriculares nacionais para o ensino médio (PCNEM). http://portal.mec.gov.br/seb/arquivos/pdf/ciencian.pdf.

ROSA, L.S.; GONÇALVES, R.; RODRIGUES, T.; FAGUNDES, F.M.; TIEPPO, K.; ISOTON, M.; RIBEIRO, P.S.; CARPES, F.P.; MELLO, E.M.B.; MELLO-CARPES, P.B. 2013. Difusão da fisiologia através da capacitação de docentes da educação básica. Revista Ciência em Extensão. 9(2): 128-140.

CAMPOS, L.M.L.; BORTOLOTO, T.M.; FELÍCIO, A.K.C. 2003. A produção de jogos didáticos para o ensino de ciências e biologia: uma proposta para favorecer a aprendizagem. Cadernos dos Núcleos de Ensino. P.35-48.

SAVI, R.; ULBRICHT, V. 2008. Jogos digitais educacionais: benefícios e desafios. RENOTE - Revista Novas Tecnologias na Educação. 6(2).

CAREY, R. 2015 [online]. Game design canvas explained. Homepage: http://richardcarey.net/game-design-canvas/ 